\title{
Cytohistological correlation of conventional Papanicolaou smears in cervical neoplasia at a tertiary care hospital of Nepal
}

\author{
Anuj Poudel ${ }^{1}$, Prahar Dahal ${ }^{1}$ \\ ${ }^{I}$ Department of Pathology, Universal College of Medical Sciences, Bhairahawa, Nepal
}

\author{
Keywords: \\ Cervix; \\ Intraepithelial neoplasm; \\ Pap Smear; \\ Squamous \\ Intraepithelial Lesion;
}

\begin{abstract}
Background: Conventional Cervical Cytology is the most widely used cervical cancer screening test. The incidence of cervical carcinoma is incredibly high in developing countries due to lack of proper knowledge. The extensive use of cervical screening with Papanicolau smears had considerably increased the detection of precancerous and cancerous lesion of uterine cervix. Study was conducted to evaluate cytohistological correlation and to calculate concordance and discordance of Pap smear in detection of precancerous and cancerous lesions of uterine cervix.
\end{abstract}

Materials and Methods: A total of 54 samples reported in Pap smear as cervical intraepithelial lesions and suspicious for invasive malignancies were selected and correlated with corresponding histopathological findings. It was an observational study done for a period of 18 months from November 2016 to May 2018. All the statistical evaluation was done by using SPSS version 20.

Results: During the study period 54 cases were evaluated. Atypical Squamous Cell of Undetermined Significance was the common abnormal findings in the Pap smear with frequency of $26(48.1 \%)$. Out of total 54 cases of Pap smears, 30 (55.55\%) were concordant while discrepancies occurred in $24(44.44 \%)$ cases with cervical biopsy

Conclusions: The study revealed a good correlation between cervical cytology and cervical biopsy. We also concluded that conventional Pap smear is a cost effective test for the early detection of precancerous and cancerous cervical lesions.

\section{Correspondence:}

Dr. Anuj Poudel, MD

Associate Professor, Department of Pathology,

Universal College of Medical Sciences, Bhairahawa, Nepal

ORCID ID: 0000-0002-6304-4911

Email:dranujpoudel@gmail.com

Received : February $7^{\text {th }} 2019$; Accepted : March14 $4^{\text {th }} 2019$; Published : March $29^{\text {th }} 2019$

Citation: Poudel A, Dahal P. Cytohistological correlation of conventional Papanicolaou smears in cervical neoplasia at a tertiary care hospital of Nepal. J Pathol Nep 2019;9:1475-9. DOI 10.3126/jpn. v9i1.23372

Copyright: This is an open-access article distributed under the terms of the Creative Commons Attribution 4.0 International License, which permits unrestricted use, distribution, and reproduction in any medium, provided the original author and source are credited.

\section{INTRODUCTION}

Cervical cancer is fourth common cancer affecting women and also fourth common cause of cancer death in women, worldwide. Seventy percent of it occurs in developing countries. ${ }^{1}$ However, it is most common cancer among Nepalese women. ${ }^{2}$ According to the International Agency for Research on Cancer, the incidence of cervical cancer can be reduced by $90 \%$ through periodic screening. ${ }^{3}$ The human papillomavirus (HPV) plays a central role in cervical carcinogenesis, and around it revolve various factors that directly or indirectly influence whether or not changes in the cervical squamous epithelium occurs that can evolve into 
cancer. Among the factors most studied are immunological factors, smoking, age, pregnancy (multiple child birth), use of hormonal contraceptives and microbiota. ${ }^{4}$

Cervical cytology has been successful in reducing the incidence and mortality but several reviews of the efficacy of cervical cytology suggested a high false negative rate because of the error occurring at various stages like sampling preparation, interpretation of cervical smears. ${ }^{5}$ The uterine cervix, being the most exposed part of the female reproductive system, is more vulnerable to get diseased, particularly in peri- \& post-menopausal age group women. The lesion may be inflammatory, pre-neoplastic and neoplastic. Neoplastic as well as preneoplastic lesions if detected in time can be treated. The treatment is effective in reducing the chance of progression to malignant disease. ${ }^{6}$

Pap smear is a screening test only. Positive test requires further investigation like colposcopy, cervical biopsy and fractional curettage. Pap smear can detect $70-95 \%$ of cancer of the cervix and about $70 \%$ of endometrial cancer shown in different studies. ${ }^{7}$ Monitoring cytohistologic discrepancies is a useful quality assurance tool in cytology laboratory. As a part of continuous quality improvement program, cytohistologic correlation may help laboratories to refine diagnostic criteria and improve diagnostic accuracy and reproducibility. ${ }^{8}$ Although high-risk Human Papillomavirus (HR-HPV) test and HPV genotyping have certain role in cervical cancer screening nowadays, these tests are not widely available in developing countries. Cervical cytology is still the principal screening method. ${ }^{9}$

Hence, this study was undertaken to classify lesions of abnormal Pap smear according to The Bethesda System 2014 and to study the concordance and discordance between abnormal Pap smear findings and corresponding histopathological findings.

\section{MATERIALS AND METHODS}

This is a hospital based analytical study conducted among patients attending Obstetrics/Gynaecology(OBS/GYN) outpatient department(OPD) and inpatient department(IPD) at UCMS-TH, Bhairahawa, Nepal whose cervical biopsy was taken to correlate precancerous and cancerous cervical lesion on Pap smear. The ethical approval for study was taken from Institutional Review committe, Universal College of Medical Sciences (UCMS-TH) before sample collection.

Correlation study between Pap smear findings and cervical biopsies findings over an 18 months period from November 2016 to May 2018 were conducted in patients suspected as premalignant or malignant cervical lesion.

Cervical exfoliative cytology slides were transferred directly from alcohol -ether fixative without drying and stained with conventional Papanicolau staining technique. Cervical biopsy specimen were fixed in formalin $(10 \%)$, processed and stained with Hematoxylin and Eosin for histopathological examination. Abnormal cervical Pap smear findings were reported as per guidelines by The Bethesda System 2014 and biopsies were advised for correlation.

For the purpose of calculating concordant and discordant cases following entities were considered equivalent:

- ASCUS in Pap smear was considered concordant with HPE diagnosis of CIN I/ Koilocytic atypia.

- LSIL in Pap smear was considered concordant with HPE diagnosis of CIN I/ Koilocytic atypia.

- HSIL in Pap smear was considered concordant with HPE diagnosis of CIN II/CIN III.

- HSIL suspicious of invasion was considered concordant with HPE diagnosis of SCC.

The study population consisted of women with abnormal Pap smear findings who underwent cervical biopsy examination excluding all the cases of Negative for Intraepithelial Lesion or Malignancy (NILM). Statistical analysis was performed using Microsoft Excel 2010 and SPSS version 20.

\section{RESULTS}

A total of 54 cases were enrolled in the study. All these patients had abnormal Pap smear finding that felled in category of Epithelial Cell abnormality according to the criteria of TBS-2014. All patients were interviewed in detail as per proforma. The data recorded were analyzed statistically and following observations and results were obtained.

Among the study population Atypical squamous cell of undetermined significance was the most common abnormal findings $(n=26 ; 48.1 \%)$ followed by LSIL $(n=19 ; 35.2 \%)$ and HSIL $(n=6 ; 11.1 \%)$. HSIL with suspicious of invasion was the least common seen only in $3(5.6 \%)$ cases.

Out of 26 cases of ASCUS, 14 cases were diagnosed as chronic cervicitis followed by 10 cases of CIN I. (Table 1) Five cases of LSIL cases in Pap smears were CIN II in biopsy specimen. All 3 suspicious cases of invasive carcinoma in Pap smears were invasive squamous cell carcinoma. (Table1) When the cyto-histological diagnoses were correlated, it was found that all 3 cases of HSIL suspicious of invasion were concordant with histopathological diagnosis of squamous cell carcinoma followed by HSIL in which 4 out of 6 cases were concordant with HPE diagnosis of CIN II. (Table 2) Out of total 54 cases, 30 (55.55\%) were concordant while discrepancies occurred in $24(44.44 \%)$ 
Table 1: Comparison between histopathological diagnosis with pap smear $(n=54)$.

\begin{tabular}{lllccccc}
\hline & & \multicolumn{4}{c}{ Histopathological diagnosis } & \multicolumn{2}{c}{ Total } \\
\cline { 3 - 7 } & & Chronic Cervicitis & Koilocytic atypia & CIN I & CIN II & $\begin{array}{c}\text { Squamous Cell } \\
\text { Carcinoma }\end{array}$ \\
\cline { 3 - 8 } & ASCUS & 14 & 2 & 10 & 0 & 0 & 26 \\
PAP smear & LSIL & 2 & 0 & 11 & 5 & 1 & 19 \\
& HSIL & 1 & 1 & 0 & 4 & 0 & 3 \\
\hline Total & suspicious of invasion & 0 & 0 & 0 & 0 & 3 \\
\hline
\end{tabular}

Table 2: Concordance and discordance cases between Pap smear and cervical biopsy in different categories $(\mathrm{n}=54)$.

\begin{tabular}{lccc}
\hline Pap Smear Diagnosis & Concordant Cases & Discordant Cases & Total cases \\
\hline ASCUS & 12 & 14 & 26 \\
LSIL & 11 & 08 & 19 \\
HSIL & 04 & 02 & 06 \\
HSIL SUSPICIOUS OF INVASION & 03 & 00 & 03 \\
\hline TOTAL & $\mathbf{3 0}(\mathbf{5 5 . 5 5 \% )}$ & $\mathbf{2 4}(\mathbf{4 4 . 4 4 \% )}$ & $\mathbf{5 4}(\mathbf{1 0 0 \% )}$ \\
\hline
\end{tabular}

cases which is shown in table 2 .

When discrepant cases were analyzed it was found that 14 cases of ASCUS, 2 cases of LSIL and 1 case of HSIL on Pap smear, 3 were downgraded as Chronic cervicitis on cervical biopsy. Similarly, 5 cases of LSIL were upgraded as CIN II and 1 case was upgraded as SCC. One case of HSIL was downgraded as Koilocytic atypia on histopathology.

\section{DISCUSSION}

Cancer cervix is considered to be an ideal gynecological malignancy for screening as it meets both test and disease criteria for screening. It has a long latent phase during which it can be detected as identifiable and treatable premalignant lesions which precede the invasive disease and the benefit of conducting screening for carcinoma cervix exceeds the cost involved. ${ }^{10}$

In this study, among abnormal Pap smear findings ASCUS was most common accounting for $48.1 \%$ of cases. Similar results were seen in study by Fazia HAQ Nwaz et al, ${ }^{11}$ Chaudhary RD et al, ${ }^{12}$ Yeoh G et al. ${ }^{13}$ and Bodal V et al. ${ }^{14}$ where most common abnormal Pap smear finding was also ASCUS accounting for $47.08 \%, 50.0 \%, 65.9 \%$ and 25.67 $\%$ cases respectively.

Whereas in studies by Naik R et al, ${ }^{4}$ Jyothi R et al, ${ }^{15}$ Sachan PL et al. ${ }^{16}$, Jones B et al, ${ }^{17}$ Vidhyadhar S et al., ${ }^{18}$ Verma I et al, ${ }^{19}$ Malpani $\mathrm{G}$ et al, ${ }^{10}$ Joshi $\mathrm{C}$ et al, ${ }^{20}$ Laxmi RC et al ${ }^{21}$, Meenai FJ et al. ${ }^{22}$ and Bhavani $\mathrm{K}$ et $\mathrm{al}^{23}$ most common epithelial cell abnormality was LSIL accounting for $45 \%$, $48.93 \%, 60 \%, 62.5 \%, 38.88 \%, 41.7 \%, 28.16 \%, 47.22 \%$, $49.43 \%, 33.92 \%$ and $44.26 \%$ respectively among all pre invasive and invasive cases. Contrast to all of these studies including our study, HSIL was the most common epithelial cell abnormality in study by Dhakal R et al. ${ }^{24}$
In the present study, most common HPE diagnosis among women with abnormal Pap smear diagnosis is CIN I which accounts for $39 \%$ of cases. Similar findings with most common HPE diagnosis of CIN I in women with abnormal Pap smear were observed in studies by Vidhyadhar S et al, ${ }^{18}$ Malpani $\mathrm{G}$ et al, ${ }^{25}$ accounting for $54.68 \%$ and 26.05 $\%$, cases respectively. Contrary to these, SCC was most common HPE findings among women with abnormal Pap smear accounting for $69.5 \%$ of cases in a study by Vaishali Jain et al. ${ }^{26}$

Even though we excluded the NILM cases in Pap smear, we still found $31.5 \%$ cases of chronic cervicitis. Similar type of findings were also observed in a study by Meenai FJ et al. ${ }^{22}$ where even after excluding NILM in Pap smear 49 ( $17.5 \%$ ) cases of chronic cervicitis, single case of chronic cervicitis with squamous metaplasia and 6 cases of papillary endocervicitis were found.

In our study, 4 cases of SCC were observed in HPE accounting for $7.4 \%$ of total cases. Similar finding was seen in a study by Laxmi RC et al. ${ }^{21}$ where SCC accounts for 8.98 $\%$ of cases in women with abnormal Pap smear. Whereas in a study by V. Bodal et al. ${ }^{14}$ and Jain V et al, ${ }^{26}$ SCC accounts for $35.13 \%$ and $69.5 \%$ cases respectively among women with abnormal Pap smear.

In the present study $68.51 \%$ of women with abnormal Pap have abnormal histopathology of CIN and SCC. Similarly, in a study by Sahida Akhter et al.27 58.3\% of patients had abnormal histopathology.

Twelve cases of ASCUS correlated with CIN I/Koilocytic atypia and 14 cases were downgraded as chronic cervicitis in the present study. Similar finding was also observed in a study by Meenai $\mathrm{F}$ J et al. ${ }^{22}$ where 55 cases belonging to ASCUS category reported on cervical cytology were 
diagnosed as CIN I (27 cases), 24 cases were downgraded as chronic cervicitis and 4 cases were upgraded as CIN II on cervical biopsy.

In a study by Ramadevi $\mathrm{E}$ et al. ${ }^{28}$ Pap smear correctly estimated CIN in 78\%, underestimated in $10 \%$ and overestimated in $12 \%$ of cases. Whereas in our study Pap smear correctly estimated CIN in only $60 \%$ of cases, underestimated in $16 \%$ and overestimated in $24 \%$ of cases.

In this study for diagnosis of SCC in cervical biopsy three out of four cases had previous Pap diagnosis of HSIL suspicious of invasion. Similar finding was observed in a study by Miller RA et al. ${ }^{29}$ where for diagnosis of SCC most frequently observed previous Pap test diagnosis was HSIL or above before or at the time of tissue diagnosis.

Concordance rate for SCC in our study was 100 percent. It is consistent with a study by Naik R et al4 where concordance rate for malignancy was 100 percent. Whereas in a study by Vaishali Jain et al. ${ }^{26}$ corcordance rate for SCC was 83.6 $\%$ and in a study by Meenai FJ et al. ${ }^{22}$ concordance rate for SCC was 90.47 percent.

In our study concordance and discordance between Pap smear and HPE diagnosis is $55.55 \%$ and $44.44 \%$ respectively. In other studies concordance is quite higher than our study. In a study by Meenai FJ et al. ${ }^{22}$ total number of concordant cases were $68.57 \%$ and discordant cases were $31.43 \%$ respectively.

Similarly, in a study by Vaishali Jain et al. ${ }^{26}$ overall concordance rate was $70.7 \%$ and concordance of cytology and histopathology was $89.3 \%$ in a study by Jyothi R et al. ${ }^{15}$

\section{CONSLUSION}

Pap smear is important screening tools for detection of precancerous and cancerous cervical lesions of the cervix. However, it is necessary to perform cervical biopsy which is gold standard if any epithelial abnormalities are detected in cervical cytology for confirmation. The study revealed a good correlation between cervical cytology and cervical biopsy. In the present study, we have correlated abnormal Pap smear findings with that of HP diagnosis, considering HPE as gold standard. We conclude that conventional Pap smear is a cost effective method for early detection of premalignant and malignant cervical lesions and secondary prevention of carcinoma cervix.

\section{Conflict of interest: None}

\section{REFERENCES}

1. Ferlay J, Soerjomataram I, Dikshit R, Eser S, Mathers C, Rebelo M, Parkin DM, Forman D, Bray F. Cancer incidence and mortality worldwide: sources, methods and major patterns in Globocan 2012. Int J cancer. 2015;136:359-86. Crossref
2. Family Health Division. National Guideline for Cervical Cancer Screening and Prevention in Nepal. Minist Heal Popul Gov Nepal, Kathmandu, Nepal. 2010.

3. IARC Working Group on Evaluation of Cervical Cancer Screening Programmes. Screening for squamous cervical cancer: duration of low risk after negative results of cervical cytology and its implication for screening policies. Br Med J (Clin Res Ed). 1986;293(6548):65964. Crossref

4. Naik R, Am M, Pandar, Satpathi S, Pk B, Km P. Cytohistological correlation and accuracy of the pap smear test in diagnosis of cervical lesions: a hospital based cross-sectional study from Odisha, India. Medical Science 2015;3:242-9. Crossref

5. Stalf A, Wilkins EJ MR. Detection of cervical neoplasia the risk error. Clin Obstet Gynecol. 1979;16:238.

6. Nasheen Fathima K, Patil AM, Patil S, Sajjanar BB, Yendigeri $\mathrm{SM}$,ArifullaK. Cyto- histological correlation of cervix lesion. Unique Journal of Medical and Dental Sciences. 2016;4:28-30. Crossref

7. Nandakumar A, Ramnath T, Chaturvedi M. The magnitude of cancer cervix in India. Indian J Med Res. 2009;130:219-21.

8. Mody DR, Davey DD, Branca M, et al. Quality assurance and risk reduction guidelines. Acta Cytol. 2000;44:496-507. Crossref

9. Kietpeerakool C, Tangjitgamol S, Srisomboon J. Histopathological outcomes of women with abnormal cervical cytology: a review of literature in Thailand. Asian Pac J Cancer Prev. 2014;15:6489-94. $\underline{\text { Crossref }}$

10. Gupta R, Gupta SG, Mishra KB, Singh RL, Doctor R. Pattern of Pap smear Cytology and Its Histopathological Correlation at a Tertiary Care Center. Rec Adv Path Lab Med 2016;2:13-9.

11. HAQ Nawaz F, Aziz AB, Pervez S, Rizvi JH. Prevalence of abnormal Papanicolaou smears and cytohistological correlation: A study from Aga Khan University Hospital, Pakistan. Asia Pac J Clin Oncol. 2005;1:128-32. Crossref

12. Chaudhary RD, Inamdar SA, Hariharan C. Correlation of diagnostic efficacy of unhealthy cervix by cytology, colposcopy and histopathology in women of rural areas. Int J Reprod Contracept Obstet Gynecol 2016 24;3:213-8.

13. Yeoh GP, Chan KW. The accuracy of Papanicolaou smear predictions: cytohistological correlation of 283 cases. Hong Kong Med J. 1997;3:373-6. Crossref

14. Bodal VK, Brar RK, Bal MS. Correlation of Pap Smear with Histopathological Findings in. Glob J Med Res E Gynecol Obstet. 2014;14:18-24.

15. Jyothi R, Gupta P, Rao R, Sood PL, Parasher N. Correlation between Colposcopy, Cytology and Histopathology in High-risk Patients for Cervical Cancer in Perimenopausal Women in Himachal Pradesh, India. Journal of SAFOMS. 2013;1:21. Crossref

16. Sachan PL, Singh M, Patel ML, Sachan R. A Study on Cervical Cancer Screening Using Pap Smear Test and Clinical Correlation. Asia Pac J Oncol Nurs. 2018;5:337-41. Crossref

17. Jones BA, Novis DA. Cervical biopsy-cytology correlation: A College of American Pathologists Q-Probes study of 22439 correlations in 348 laboratories. Arch Pathol Lab Med. 1996;120:523-31. Crossref

18. Vidyadhar DS, Bhattacharya DA, Bohara DS, Dwivedi DA, Agarwal DA, Gangwar DD. Comparison and Correlation of Cytology, Colposcopy and Histopathology of Premalignant Lesions of Cervix In Rural Women of Barabanki District. IOSR J Dent Med Sci. 2017; 16:13-8. Crossref

19. Verma I, JaIn V, Kaur T. Application of bethesda system for cervical cytology in unhealthy cervix. J Clin Diagn Res. 2014;8:26-30. $\underline{\text { Crossref }}$

20. Warpe BM, Warpe SJ, Sawant SS. An institution-based cervical PAP smear study, correlation with clinical findings \& histopathology in the Konkan region of Maharashtra state, India. Walawalkar International 
Medical Journal. 2016;3:3751.

21. Laxmi RC, Shrestha P, Pradhan B. Analysis of Cervical Cancer Screening at Patan Hospital Nepal. Journal of Chitwan Medical College. 2018;8:1-4.

22. Meenai FJ, Ansari SA, Gupta S, Ali MA. Cyto-histo correlation of conventional Pap smear with cervical biopsy in diagnosis of precancerous and cancerous lesions of cervix. IP Archives of Cytology and Histopathology Research. 2018;3(2):76-82. DOI: 10.18231/2456-9267.2018.0016. Crossref

23. Bhavani K, Vijaya Sheela P, Vani I, et al. Study of cervical cytology in papanicolaou smears in a tertiary care center. Int Arch Integr Med 2017;4:172-6.

24. Dhakal R, Makaju R, Sharma S, Bhandari S, Shrestha S, Bastakoti R. Correlation of Cervical Pap Smear with Biopsy in the Lesion of Cervix. Kathmandu Univ Med J . 2016;14:254-7.

25. Malpani G, Agrawal P, Varma AV, Khandelwal N, Tignath G. Cervical Pap smear study and detection of abnormal epithelial lesions and determination of its accuracy by cytohistological correlation in patients of tertiary care teaching hospital in central India. Int J Reprod Contracept Obstet Gynecol. 2017;5:2312-6.
26. Jain RV. Screening for Carcinoma Cervix with Simultaneous use of PAP smear, colposcopy guided cervical biopsy-A prospective study. Pariplex -Indian journal of research. 2018;6(4):7-8. Crossref

27. Akhter S, Bari A, Hayat Z. Variability study between Pap smear, Colposcopy and Cervical Histopathology findings. J Pak Med Assoc. 2015;65:1295-9. Crossref

28. Ramadevi E, Mamata N, Madhavi GB, Sudha Rani V, Padmalatha R, Shamili G. A Study of Correlation between Cytology and Histopathology with Colposcopic Findings. Int J Intg Med Sci. 2017:4:477-83

29. Miller RA, Waters LL, Mody DR, Tams KC. Squamous cell carcinoma of the cervix: A cytology-histology-human papillomavirus correlation in clinical practice. Arch Pathol Lab Med. 2015;139:77681. Crossref 